\title{
M520, Rat Strain
}

National Cancer Institute

\section{Source}

National Cancer Institute. M520, Rat Strain. NCI Thesaurus. Code C14409.

Low frequency of pancreatic exocrine tumors. By 12-15 months of age develop small local areas of nephritis that progress by 22-24 months to moderate to severe nephritis in 75\% of animals (Snell 1967). About 33\% of females over 18 months develop tumors of the uterus of endometrial origin. Adrenocortical adenomas (about 20\% in males and 40\% in females over 18 months of age), and phaeochromocytomas or preneoplastic nodules in adrenal medulla (about $67 \%$ of males over 21 months of age) (Snell 1965). Low blood pressure (21/23), reaching 121_1.2 (SEM) mmHg at 10 weeks of age. Resistant to development of methylcholanthrene -induced thyroiditis (Glover et al 1969). 